\title{
Velocidade de Estabelecimento de Acessos de Amendoim Forrageiro na Amazônia Ocidental
}

\section{Judson Ferreira Valentim ${ }^{1}$, Carlos Mauricio Soares de Andrade ${ }^{2}$, Hélia Alves de Mendonça ${ }^{3}$, Maykel Franklin Lima Sales ${ }^{4}$}

\begin{abstract}
RESUMO - O objetivo deste estudo foi avaliar a velocidade de estabelecimento de acessos de amendoim forrageiro (Arachis repens e Arachis pintoi), visando selecionar materiais adaptados aos sistemas intensivos de produção pecuária do Acre. O delineamento experimental utilizado foi de blocos casualizados, com quatro repetições. Os tratamentos consistiram de dois acessos deA. repens, sete acessos e duas cultivares deArachis pintoiidentificados como promissores para as condições ambientais de Rio Branco, Acre. Foi adotado como testemunha A. pintoi cv. Amarillo. Os acessos Ap 65, Ap 39 e Ar 10, com desempenho semelhante às cultivares Amarillo e Belmonte, destacaram-se por apresentar excelente velocidade de estabelecimento, com índice de sobrevivência das mudas e cobertura do solo superiores a $80 \%$ e comprimento dos estolões acima de $85 \mathrm{~cm}$, respectivamente, aos 50, 70 e 120 dias após o plantio. Estes genótipos apresentaram produtividade de matéria seca (MS) superior a $2.300 \mathrm{~kg} / \mathrm{ha}$, taxas de acúmulo de MS iguais ou superiores a $20 \mathrm{~kg} / \mathrm{ha} / \mathrm{dia}$ e teor de proteína bruta variando entre 17,9 e 21,7\%, no final do período de estabelecimento. Entre os quatro grupos heteróticos, o formado pelo acesso Ap 39 destacou-se dos demais, por apresentar valores médios a altos para todas as características avaliadas, de acordo com a análise de agrupamento realizada pelo Método de Otimização de Tocher, com base na distância generalizada de Mahalanobis. Para que os materiais promissores possam ser recomendados para uso nos sistemas intensivos de produção de bovinos no Acre, devem ser desenvolvidos estudos adicionais com relação à: 1) produtividade e qualidade de MS nos períodos chuvoso e seco; 2) ocorrência de pragas e doenças; 3) produção de sementes; 4) adaptação a solos de baixa permeabilidade; 5) compatibilidade com gramíneas forrageiras e espécies arbóreas e arbustivas perenes; 6) produção animal e persistência sob pastejo.
\end{abstract}

Palavras-chave: Amarillo, Arachis pintoi, Arachis repens, Belmonte, diversidade genética, leguminosa

\section{Speed of Establishment of Accessions of Forage Peanut in the Western Amazon}

\begin{abstract}
The objective of this study was to evaluate the speed of establishment of accessions of Arachis repens and Arachis pintoi with the purpose of selecting materials capable of producing adequate quantities of high quality forage, according to the requirements of the intensive cattle production systems of Acre. The experimental design was a randomized block with four replications. The treatments consisted of two accessions of Arachis repen, seven accession and two cultivars of Arachis pintoi, identified as promising for the environmental conditions of Rio Branco, Acre. The control treatment was A. pintoi cv. Amarillo. The accessions Ap 65, Ap 39 and Ar 10, with performance similar to the cultivars Amarillo and Belmonte, were selected because of their excellent speed of establishment with index of survival of stolon and rhizome plantings and ground cover higher than $80 \%$ and length of stolons above $85 \mathrm{~cm}$, respectively, 50,70 and 120 days after planting. These genotypes showed DM yields above $2,300 \mathrm{~kg} / \mathrm{ha}, \mathrm{DM}$ accumulation rates equal or superior to $20 \mathrm{~kg} / \mathrm{ha} / \mathrm{day}$ and crude protein content ranging from 17.9 to $21.7 \%$, at the end of the establishment period. Among the four heterotic groups, the one consisting of accession Ap 39 outranked the others by presenting high mean values for all the characteristics evaluated according to the cluster analysis by the Tocher Optimization Method, based on the generalized Mahalanobis. For the recommendation of the promising accessions for use in the intensive cattle production systems in Acre, additional studies should be conducted in relation to: 1) dry matter yield and quality during the rainy and dry seasons; 2) occurrence of pests and diseases; 3) seed production; 4) adaptation to low permability soils; 5) compatibility with grasses and shrub and tree species; 6) animal production and persistence under grazing.
\end{abstract}

Key Words: Amarillo, Arachis pintoi, Arachis repens, Belmonte, genetic diversity, legume

\section{Introdução}

O uso de espécies de gramíneas adaptadas às condições de clima e solo da região e a formação de pastagens consorciadas com leguminosas tem se mostrado como alternativas econômicamente viáveis para o desenvolvimento de sistemas sustentáveis de produção de bovinos no Acre. Valentim \& Carneiro (2001) citam que em torno de $30 \%$ das pastagens do Estado são de gramíneas consorciadas

\footnotetext{
${ }^{1}$ Eng. Agr., Ph.D., Pesquisador da Embrapa Acre, Caixa Postal 3921, CEP:69908-970, Rio Branco-AC. E.mail:judson@cpafac.embrapa.br ${ }^{2}$ Eng. Agr., M.Sc., Pesquisador da Embrapa Acre. E.mail: mauricio@cpafac.embrapa.br

${ }^{3}$ Eng. Agr. D.Sc., Pesquisadora da Embrapa Acre. E.mail: helia@cpafac.embrapa.br

${ }^{4}$ Eng. Agr. Mestrando na Universidade Federal de Viçosa. E.mail: maykelsales@bol.com.br
} 
com a leguminosa Pueraria phaseoloides. No entanto, a utilização de sistemas pecuários mais intensivos tem afetado a persistência dessa leguminosa em pastagens consorciadas, levando os produtores a buscarem espécies mais adaptadas a estas condições de manejo (Valentim et al., 2000).

Leguminosas do gênero Arachis, conhecidas como amendoim forrageiro, têm sido recomendadas para alimentação animal na América do Sul (Pizarro \& Rincón, 1994), América Central (Argel, 1994), América do Norte (Prine et al., 1981; 1986; French et al., 1994) e Austrália (Cook et al., 1994). Estudos realizados em diversas condições ambientais do Brasil (Santana et al., 1998; Pizarro et al., 1992; Pizarro \& Carvalho, 1992; Carneiro et al., 2000) têm identificado acessos de $A$. pintoi com produtividade e qualidade superior à cultivar Amarillo, a mais difundida entre os produtores da América Central e América do Sul. Segundo Lascano (1994), Santana et al. (1998) e Barcellos et al. (2000), o amendoim forrageiro pode ser usado na formação de pastagens consorciadas, suportando taxas de lotação de até 4 novilhos/ha, com ganhos de peso vivo superiores a 550 g/animal.dia e $500 \mathrm{~kg} / \mathrm{ha}$.ano.

Além deA. pintoicv. Amarillo, a cultivar Belmonte está despertando grande interesse de produtores que buscam leguminosas que se adaptem às condições de clima e solo do Acre, que apresentem boa capacidade de associação com gramíneas e persistência sob pastejo nos sistemas de produção que utilizam altas taxas de lotação (Valentim et al., 2000; 2001).

$\mathrm{O}$ estabelecimento lento limita o sucesso do amendoim forrageiro como cultura de cobertura do solo, especialmente em área com alta incidência de plantas invasoras. O estabelecimento desta leguminosa é mais rápido quando o plantio é feito por sementes do que quando são utilizados estolões. Porém, o amendoim forrageiro é frequentemente plantado por meio de material vegetativo, uma vez que algumas cultivares produzem poucas sementes e a colheita destas no solo é muito difícil (Fisher \& Cruz, 1994).

Diversos estudos mostram que o estabelecimento le nto do amendoim forrageiro parece estar relacionado a fatores como: 1) forma de preparo da área; 2) características físicas e químicas do solo; 3) disponibilidade de água no solo; 4) densidade de plantio; e 5) viabilidade das sementes ou mudas (Baruch \& Fisher, 1992; Argel \& Pizarro, 1992; de la Cruz et al., 1994).
Pizarro \& Rincón (1994) acreditam que é possível selecionar novos materiais com maior velocidade de estabelecimento que as atuais cultivares. Além da velocidade de crescimento, é desejável que os novos materiais sejam produtivos e apresentem forragem de alta qualidade. Desse modo, é necessário avaliar vários genótipos que apresentem variabilidade para os caracteres desejáveis. Assim, o estudo da variabilidade genética em plantas é um pré-requisito essencial para a identificação de genótipos superiores. Entre as técnicas multivariadas disponíveis, as variáveis canônicas e a análise de agrupamento a partir das distâncias de Mahalanobis (D2) têm sido as mais usadas na avaliação da divergência genética em várias espécies (Ribeiro et al., 1999; Daher et al., 2000; Nascimento Filho et al., 2001).

O objetivo deste estudo foi avaliar e selecionar genótipos de amendoim forrageiro capazes de aliar alta velocidade de estabelecimento com boa capacidade de produção de forragem, de qualidade elevada, para serem utilizados em sistemas intensivos de produção pecuária, e como cobertura do solo em sistemas agroflorestais, na Amazônia Ocidental.

\section{Material e Métodos}

O estudo foi realizado no campo experimental da Embrapa Acre, localizado no município de Rio Branco-AC. O ecossistema da região é de floresta tropical úmida. A temperatura média anual é de $24,3^{\circ} \mathrm{C}$, com umidade relativa do ar de $84 \%$, pluviosidade média anual de $1.860 \mathrm{~mm}$, com período chuvoso de outubro a abril e déficit hídrico nos meses de junho a setembro (Embrapa, 1995).

O solo da área é do tipo Argissolo Vermelho Amarelo. A análise química, na camada de $0-20 \mathrm{~cm}$, apresentou $4 \mathrm{mg} / \mathrm{dm}^{3}$ de fósforo, $51 \mathrm{mg} / \mathrm{dm}^{3} \mathrm{de}$ potássio, $5 \mathrm{mg} / \mathrm{dm}^{3}$ de sódio, $2,1 \mathrm{cmol}_{c} / \mathrm{dm}^{3}$ de cálcio + magnésio, 0,1 cmol $/ \mathrm{dm}^{3}$ de alumínio trocável, $2,3 \mathrm{cmol} / \mathrm{cm}^{3}$ de alumínio + hidrogênio e $\mathrm{pH}=4,5$.

Avaliaram-se dois acessos de Arachis repens, sete acessos e duas cultivares de Arachis pintoi, utilizando a cultivar Amarillo como testemunha, no delineamento de blocos casualizados, com quatro repetições.

O plantio foi realizado com material vegetativo (estolões), em 5 de janeiro de 2000. As parcelas consistiram de cinco linhas de dois metros de comprimento, com espaçamento de $0,50 \mathrm{~m}$ entre linhas. Os estolões, com cerca de $30 \mathrm{~cm}$ de comprimento, foram 
plantados em intervalos de $0,25 \mathrm{~m}$ nas linhas, no total de 45 mudas por parcela. A área útil da parcela $\left(1,0 \mathrm{~m}^{2}\right)$ compreendeu duas linhas centrais, descartando $0,50 \mathrm{~m}$ em cada extremidade da linha como bordadura.

A adubação de estabelecimento constou da aplicação, a lanço, de $45 \mathrm{~kg} / \mathrm{ha}$ de $\mathrm{P}_{2} \mathrm{O}_{5}$, na forma de superfosfato simples, e de $40 \mathrm{~kg} / \mathrm{ha}$ de FTE BR-10 para suprir os micronutrientes necessários para o bom estabelecimento da leguminosa. Como tratos culturais, foram realizadas duas capinas, aos 28 e 56 dias após o plantio, para o controle das plantas invasoras.

Foram realizadas as seguintes avaliações: a) índice de sobrevivência das mudas (ISM); b) crescimento lateral dos estolões (CLE); c) cobertura do solo (CS); d) altura das plantas (AP); e) vigor das plantas (VP); f) produção e taxa de acúmulo de matéria seca (PMS e TAMS); g) teor e produção de proteína bruta (TPB e PPB).

O ISM foi calculado com base no número de plantas existentes em cada parcela após 50 dias, em relação ao número de estolões plantados. O CLE $(\mathrm{cm})$ foi avaliado 120 dias após o plantio e consistiu na média do comprimento de 10 estolões de plantas localizadas na área útil da parcela. A CS (\%) foi estimada visualmente na área útil, 70 dias após o plantio. As variáveis AP, VP, PMS, TPB e PPB foram avaliadas 120 dias após o plantio. O VP foi avaliado por meio da seguinte escala: 1 - péssimo; 2 - ruim; 3-regular; 4 - bom; 5 - excelente.

Para determinar a produção de matéria seca, cortou-se a biomassa aérea presente na área útil rente ao solo, coletando-se inclusive os estolões. As amostras foram pesadas e sub-amostras de $300 \mathrm{~g}$ foram colocadas para secar a $65^{\circ} \mathrm{C}$, em estufa com circulação forçada de ar, por 72 horas. As amostras secas foram pesadas e os dados, extrapolados para $\mathrm{kg} / \mathrm{ha}$ de matéria seca. As amostras secas das quatro repetições de cada genótipo foram agrupadas, moídas e então analisadas quanto ao TPB, de acordo com as recomendações de Silva (1990).

Os dados obtidos, com a exceção do TPB, foram submetidos à análise estatística univariada, utilizando o Software SISVAR (Ferreira, 2000), e as médias foram comparadas pelo teste de Scott \& Knott (1974), a 5\% de probabilidade. Em seguida, realizou-se a análise de variância multivariada para auxiliar na interpretação e avaliação da variabilidade genética global existente entre os genótipos, utilizando o programa Minitab. O critério para verificar se houve diferenças entre os vetores médios de genótipos foi de Wilks (Pimentel Gomes, 1990), com base na estatística.

A divergência genética foi estimada por meio da análise de agrupamento, em que a medida de dissimilaridade utilizada foi a distância de Mahalanobis $\left(\mathrm{D}^{2}\right)$, e o método de agrupamento, o de otimização de Tocher; a análise gráfica da divergência genética foi feita por meio das variáveis canônicas. Para essas análises, utilizou-se o programa GENES (Cruz, 1997).

\section{Resultados e Discussão}

Com base na análise de variância univariada, verificou-se que houve diferenças significativas $(\mathrm{P}<0,01)$ entre os genótipos para a maioria dos caracteres avaliados, exceto índice de sobrevivência das mudas, indicando que, a princípio, os genótipos são divergentes. Por meio da análise de variância multivariada obteve-se $\Lambda=0,00005$, correspondente a um $\mathrm{F}$ de 9,286, o qual foi significativo $(\mathrm{P}<0,01)$, confirmando o resultado da análise univariada e indicando haver divergência genética entre os genótipos.

Os genótipos de amendoim forrageiro apresentaram índices de sobrevivência das mudas estatisticamente semelhantes ( $\mathrm{P}>0,05), 50$ dias após o plantio, variando entre $81 \%$ (Ap 11) e $97 \%$ (cv. Belmonte) (Tabela 1).

O crescimento lateral dos estolões é uma característica de grande influência na velocidade de estabelecimento do amendoim forrageiro, por determinar a capacidade de colonização da área pelas plantas. No presente estudo, as cultivares Belmonte e Amarillo e os acessos Ap 61, Ar 10, Ap 65 e Ap 39, com crescimento lateral dos estolões variando entre $87 \mathrm{e}$ $102 \mathrm{~cm}, 120$ dias após o plantio, foram superiores $(\mathrm{P}<0,01)$ aos demais acessos (Tabela 1). Plantas destes acessos são capazes de emitir estolões e colonizar uma área com diâmetro médio entre $174 \mathrm{~cm}$ e $204 \mathrm{~cm}$, em um período de 120 dias de estabelecimento. Mesmo os acessos Ap 31 e Ap 11, com menor crescimento lateral dos estolões, apresentaram capacidade razoável de expansão, atingindo diâmetro médio entre 80 e $104 \mathrm{~cm}$, após 120 dias do plantio.

Dez semanas após o plantio, a cultivar Belmonte apresentou $96 \%$ de cobertura do solo, superior $(\mathrm{P}<0,05)$ aos demais genótipos (Tabela 1). A cultivar Amarillo e os acessos Ap 65, Ar 10, Ap 39 e Ap 15 apresentaram cobertura do solo acima de $80 \%$. O acesso Ap 31, com 34\% de cobertura do solo, foi o 
Tabela 1 - Índice de sobrevivência das mudas (ISM), crescimento lateral dos estolões (CLS) e cobertura do solo (CS) de genótipos de amendoim forrageiro, durante o período de estabelecimento, em Rio Branco-AC

Table 1 - Index of stolon cuttings survival (ISCS), lateral stolon growth (LSG) and ground cover (GC) of accessions of forage peanut during the establishment period in Rio Branco-AC

\begin{tabular}{lccc}
\hline Genótipos & $\mathrm{ISM}^{1}(\%)$ & $\mathrm{CLS}^{2}(\mathrm{~cm})$ & $\mathrm{CS}^{3}(\%)$ \\
Genotypes & $I S C S^{1}$ & $L^{2} G^{2}$ & $G C^{3}$ \\
\hline A. pintoi cv. Amarillo & 96 & $92^{\mathrm{a}}$ & $86^{\mathrm{b}}$ \\
A. pintoi cv. Belmonte & 97 & $102^{\mathrm{a}}$ & $96^{\mathrm{a}}$ \\
A. pintoi Ap 05 & 93 & $76^{\mathrm{b}}$ & $72^{\mathrm{c}}$ \\
A. pintoi Ap 11 & 81 & $52^{\mathrm{d}}$ & $51^{\mathrm{d}}$ \\
A. pintoi Ap 15 & 88 & $68^{\mathrm{c}}$ & $84^{\mathrm{b}}$ \\
A. pintoi Ap 31 & 84 & $40^{\mathrm{d}}$ & $34^{\mathrm{e}}$ \\
A. pintoi Ap 39 & 91 & $87^{\mathrm{a}}$ & $84^{\mathrm{b}}$ \\
A. pintoi Ap 61 & 92 & $99^{\mathrm{a}}$ & $71^{\mathrm{c}}$ \\
A. pintoi Ap 65 & 95 & $88^{\mathrm{a}}$ & $89^{\mathrm{b}}$ \\
A. repens Ar 10 & 92 & $98^{\mathrm{a}}$ & $84^{\mathrm{b}}$ \\
A. repens Ar 11 & 89 & $74^{\mathrm{c}}$ & $54^{\mathrm{d}}$ \\
CV (\%) & 8,05 & 12,40 & 10,95 \\
\hline
\end{tabular}

Médias seguidas por letras diferentes na mesma coluna, diferem entre si $(P<0,05)$ pelo teste de Scott-Knott.

${ }^{1}$ Número de mudas vivas 50 dias após o plantio em relação ao número de mudas plantadas.

2 Avaliação realizada no final do período de estabelecimento (120 dias após o plantio).

3 Avaliação realizada 70 dias após o plantio.

Means followed by different letters, in the same column, are different $(P<.05)$ by Scott-Knott test.

${ }^{1}$ Number of existing plants after 50 days of growth in relation to the number of stolon cuttings planted.

${ }^{2}$ Evaluation performed at the end of the establishment period (120 days after planting).

${ }^{3}$ Evaluation performed 70 days after planting.

que apresentou pior desempenho, sendo que, após 120 dias do plantio, este acesso ainda apresentava $70 \%$ de cobertura do solo, enquanto os demais já haviam alcançado $100 \%$ de cobertura do solo.

Portanto, nas condições ambientais do Acre, foram necessários 90 a 120 dias para que a maioria dos genótipos de amendoim forrageiro avaliados se estabelecesse e apresentasse cobertura do solo densa e uniforme. Já Argel (1994) relatou que o amendoim forrageiro CIAT 17434 (cv. Mani Mejorador) alcançou, oito semanas após o plantio, $100 \%$ de cobertura do solo, no Panamá e na Costa Rica. No entanto, Franco et al. (1992) citam que esta mesma cultivar, plantada nos trópicos úmidos, apresentou apenas $43 \%$ de cobertura do solo 12 semanas (84 dias) após o plantio.

Resultados contrastantes com a mesma cultivar ou acesso de amendoim forrageiro em diferentes condições ambientais também foram obtidos por Baruch \& Fisher (1992), Argel \& Pizarro (1992) e de la Cruz et al. (1994). Estes autores verificaram que a velocidade de estabelecimento desta leguminosa é o resultado, entre outros fatores, da forma de preparo da área, tipo do solo, disponibilidade de água no solo, densidade de plantio, viabilidade das sementes ou mudas, incidência de plantas invasoras e tratos culturais.

Em outros trabalhos também foram observadas diferenças entre genótipos na porcentagem de cobertura do solo, em determinado tempo, bem como o tempo necessário para que os genótipos alcancem $100 \%$ de cobertura do solo. Argel \& Villarreal (1998), na Colômbia, verificaram que a cultivar Porvenir (CIAT 18744) produz mais estolões com maior comprimento do que a Mani Mejorador (CIAT 17434). Segundo estes autores, isto conduz a maior número de pontos de crescimento e de raízes e à maior produção de biomassa. Por esta razão, cultivares ou acessos com estas características cobrem mais rapidamente o solo e apresentam maior capacidade de competir com as plantas invasoras durante o período de estabelecimento.

A altura média das plantas dos acessos de amendoim forrageiro Ap 65 (8,0 cm), Ap 39 (7,8 cm) e da cultivar Amarillo $(7,0 \mathrm{~cm})$ foi superior $(\mathrm{P}<0,05)$ à dos demais genótipos (Tabela 2). $\mathrm{O}$ acesso Ar 11 foi o genótipo que apresentou a menor altura das plantas $(3,8 \mathrm{~cm})$.

A cultivar Amarillo e os acessos Ap 65, Ar 10, Ap 61 apresentaram excelente vigor após 120 dias do

Tabela 2 - Altura e vigor das plantas de genótipos de amendoim forrageiro, 120 dias após o plantio, em Rio Branco-AC

Table 2 - Heightand vigor of plants of forage peanutaccessions, 120 days after planting, in Rio Branco-AC

\begin{tabular}{lcc}
\hline $\begin{array}{l}\text { Genótipos } \\
\text { Genotypes }\end{array}$ & $\begin{array}{c}\text { Altura das } \\
\text { plantas (cm) } \\
\text { Plant height }\end{array}$ & $\begin{array}{c}\text { Vigor das } \\
\text { Plantas } \\
\text { Plant vigor }\end{array}$ \\
\hline Amarillo & $7,0^{\mathrm{a}}$ & $5,0^{\mathrm{a}}$ \\
Belmonte & $6,2^{\mathrm{b}}$ & $4,6^{\mathrm{b}}$ \\
Ap 05 & $6,0^{\mathrm{b}}$ & $4,2^{\mathrm{b}}$ \\
Ap 11 & $6,0^{\mathrm{b}}$ & $3,9^{\mathrm{c}}$ \\
Ap 15 & $5,8^{\mathrm{b}}$ & $4,2^{\mathrm{b}}$ \\
Ap 31 & $6,2^{\mathrm{b}}$ & $3,0^{\mathrm{d}}$ \\
Ap 39 & $7,8^{\mathrm{a}}$ & $4,6^{\mathrm{b}}$ \\
Ap 61 & $6,0^{\mathrm{b}}$ & $4,9^{\mathrm{a}}$ \\
Ap 65 & $8,0^{\mathrm{a}}$ & $5,0^{\mathrm{a}}$ \\
Ar 10 & $5,8^{\mathrm{b}}$ & $5,0^{\mathrm{a}}$ \\
Ar 11 & $3,8^{\mathrm{c}}$ & $3,8^{\mathrm{c}}$ \\
CV (\%) & 10,70 & 7,29 \\
\hline
\end{tabular}

Médias seguidas por letras diferentes, na mesma coluna, diferem entre si $(\mathrm{P}<0,05)$ pelo teste de Scott-Knott.

1 Vigor das plantas: 1 - péssimo, 2 - ruim, 3 -regular, 4 - bom, 5 - excelente.

Means followed by different letters, in the same column, are different $(P<.05)$ by Scott-Knott test.

${ }_{1}^{1}$ Plant vigor: 1 - very bad, 2 - bad, 3 - regular, 4 -good, 5 - excellent. 
plantio, sendo superiores $(\mathrm{P}<0,05)$ aos demais genótipos (Tabela 2). A cultivar Belmonte e os acessos Ap 39, Ap 15 e Ap 05, com vigor entre bom e excelente, foram superiores $(\mathrm{P}<0,05)$ aos acessos Ap 11, Ar 11 e Ap 31, este último, inferior a todos os genótipos avaliados.

O acesso Ap 65 apresentou produção de matéria seca superior a $3.000 \mathrm{~kg} / \mathrm{ha}$, suplantando $(\mathrm{P}<0,05)$ os demais genótipos avaliados (Tabela 3). Isto representa taxa média de acúmulo de matéria seca de $25 \mathrm{~kg} / \mathrm{ha}$.dia, no período de 120 dias após o plantio. As cultivares Amarillo e Belmonte e os acessos Ap 39 e Ar 10, com PMS acima de $2.300 \mathrm{~kg} / \mathrm{ha}$ e taxa de acúmulo de matéria seca entre 20 e $22 \mathrm{~kg} / \mathrm{ha} / \mathrm{dia}$, foram superiores $(\mathrm{P}<0,05)$ aos acessos Ap 15, Ap 61, Ap 05, Ap 11, Ar 10 e Ap 31. Os acessos Ap 11, Ar 11 e Ap 31 foram os menos produtivos, com taxas de acúmulo de matéria seca inferiores a $10 \mathrm{~kg} / \mathrm{ha} / \mathrm{dia}$ (Tabela 3).

Segundo Pizarro \& Rincón (1994), estudos conduzidos em El Puyo, Equador, mostraram que uma avaliação oito meses (240 dias) após o plantio identificou acessos com $100 \%$ de cobertura do solo e produção de forragem entre 1.680 e $1.980 \mathrm{~kg} / \mathrm{ha}$, superiores à cultivar Amarillo $(990 \mathrm{~kg} / \mathrm{ha})$.

Perez et al. (1999a, 1999b), em estudo realizado no Rio Grande do Sul, verificaram que a introdução do amendoim forrageiro (A. pintoi), em pastagens já estabelecidas, pode ser feita utilizando estolões, coroas enraizadas ou sementes, obtendo produção de MS da leguminosa de até $2.000 \mathrm{~kg} / \mathrm{ha}, 152$ dias após o plantio em campo nativo, e de cerca de $500 \mathrm{~kg} / \mathrm{ha}, 102$ dias após o plantio em pastagem de Coastcross -1 .

As cultivares e acessos avaliados nesse trabalho apresentaram teores médios de proteína bruta (PB) variando de 17,9 a 21,7\%. Estes resultados, por terem incluído toda a biomassa acima do solo, são inferiores àqueles obtidos por Damé et al. (1998), que obtiveram teores de PB variando de 20,6 a $25,6 \%$, ao avaliarem sete acessos de A. pintoi no Rio Grande do Sul.

A cultivar Amarillo e os acessos Ap 65 e Ap 39 apresentaram produções de PB acima de $500 \mathrm{~kg} / \mathrm{ha}$, após 120 dias do plantio, superior $(\mathrm{P}<0,05)$ aos demais acessos (Tabela 3). A cultivar Belmonte e os acessos Ar 10, Ap 15, Ap 61 e Ap 05 foram superiores $(\mathrm{P}<0,05)$ aos acessos Ar 11, Ap 11 e Ap 31, produzindo entre 348 e $430 \mathrm{~kg} / \mathrm{ha}$ de $\mathrm{PB}$.

Na Tabela 4, estão apresentadas as correlações entre as variáveis utilizadas para determinar a velocidade de estabelecimento dos genótipos de amendoim forrageiro. As variáveis mais fortemente correlacionadas com a produção de matéria seca dos genótipos foram a \% de cobertura do solo $(\mathrm{r}=0,93)$ e o vigor das plantas $(r=0,89)$. Também merece destaque a forte associação do vigor das plantas com o crescimento lateral dos estolões $(\mathrm{r}=0,90)$ e com a $\%$ de cobertura do solo $(\mathrm{r}=0,88)$, além do índice de sobrevivência das mudas e o crescimento lateral dos estolões $(r=0,87)$. Já a variável altura das plantas apresentou-se pouco correlacionada com as demais

Tabela 3 - Produção e taxa de acúmulo de matéria seca (MS) e teor e produção de proteína bruta (PB) de genótipos de amendoim forrageiro, ao final do período de estabelecimento, em Rio Branco-AC

Table 3 - Dry matter (DM) yield and accumulation rate, crude protein (CP) content and yield of accessions of forage peanut, at the end of the establishment period, in Rio Branco-AC

\begin{tabular}{|c|c|c|c|c|}
\hline $\begin{array}{l}\text { Genótipos } \\
\text { Genotypes }\end{array}$ & $\begin{array}{c}\text { Produção de MS } \\
(\mathrm{kg} / \mathrm{ha}) \\
\text { DM yield } \\
(\mathrm{kg} / \mathrm{ha})\end{array}$ & $\begin{array}{c}\text { Taxa de acúmulo } \\
\text { de MS (kg/ha.dia) } \\
\text { DM accumulation rate } \\
\text { (kg/ha.day) }\end{array}$ & $\begin{array}{l}\text { Teor de PB } \\
\quad(\%) \\
\text { CP content } \\
(\%)\end{array}$ & $\begin{array}{c}\text { Produção de PB } \\
(\mathrm{kg} / \mathrm{ha}) \\
C P \text { yield } \\
(\mathrm{kg} / \mathrm{ha})\end{array}$ \\
\hline Amarillo & $2639^{b}$ & 22 & 19,8 & $523^{a}$ \\
\hline Belmonte & $2373^{b}$ & 20 & 17,9 & $425^{b}$ \\
\hline Ap 05 & $1728^{c}$ & 14 & 20,2 & $348^{b}$ \\
\hline Ap 11 & $1107^{d}$ & 9 & 19,7 & $218^{c}$ \\
\hline Ap 15 & $2076^{c}$ & 17 & 20,6 & $428^{b}$ \\
\hline Ap 31 & $786^{\mathrm{d}}$ & 7 & 18,3 & $144^{\mathrm{c}}$ \\
\hline Ap 39 & $2430^{b}$ & 20 & 21,7 & $526^{\mathrm{a}}$ \\
\hline Ap 61 & $1854^{\mathrm{c}}$ & 15 & 19,8 & $368^{\mathrm{b}}$ \\
\hline Ap 65 & $3011^{\mathrm{a}}$ & 25 & 19,3 & $582^{\mathrm{a}}$ \\
\hline Ar 10 & $2395^{b}$ & 20 & 18,0 & $430^{b}$ \\
\hline Ar 11 & $1072^{\mathrm{d}}$ & 9 & 20,6 & $221^{\mathrm{c}}$ \\
\hline $\mathrm{CV}(\%)$ & 17,11 & - & - & 17,64 \\
\hline
\end{tabular}

Médias seguidas por letras diferentes, na mesma coluna, diferem entre si $(\mathrm{P}<0,05)$ pelo teste de Scott-Knott.

Means followed by different letters, in the same column, are different $(P<.05)$ by Scott-Knott test. 
Tabela 4 - Coeficientes de correlação (r) entre índice de sobrevivência das mudas (ISM), crescimento lateral dos estolões (CLE), cobertura do solo (CS), altura das plantas (AP), vigor das plantas (VP) e produção de matéria seca (PMS) de genótipos de amendoim forrageiro, durante o período de estabelecimento, em Rio Branco-AC

Table 4 - Correlation coefficients ( $r$ ) among the variables index of stolon cuttings survival (ISCS), lateral stolon growth (LPG), ground cover (GC), plant height $(P H)$, plant vigor (PV) and dry matter yield $(D M Y)$ of forage peanut accessions, during the establishment period, in Rio Branco-AC

\begin{tabular}{|c|c|c|c|c|c|}
\hline $\begin{array}{l}\text { Variável } \\
\text { Variable }\end{array}$ & $\begin{array}{l}\text { CLE } \\
L P G\end{array}$ & $\begin{array}{l}\mathrm{CS} \\
G C \\
\end{array}$ & $\begin{array}{l}\text { AP } \\
P H\end{array}$ & $\begin{array}{l}\text { VP } \\
P V\end{array}$ & $\begin{array}{l}\text { PMS } \\
D M Y\end{array}$ \\
\hline $\begin{array}{l}\text { ISM } \\
\text { ISCS }\end{array}$ & $0,87 * * *$ & $0,82 * *$ & $0,31^{\mathrm{ns}}$ & $0,76^{* *}$ & $0,79 * *$ \\
\hline $\begin{array}{l}\text { CLE } \\
L P G\end{array}$ & - & $0,83 * *$ & $0,22^{\mathrm{ns}}$ & $0,90 * * *$ & $0,77 * *$ \\
\hline $\begin{array}{l}\mathrm{CS} \\
G C\end{array}$ & - & - & $0,45^{\mathrm{ns}}$ & $0,88 * * *$ & $0,93 * * *$ \\
\hline $\begin{array}{l}\text { AP } \\
P H V\end{array}$ & - & - & - & $0,45^{\mathrm{ns}}$ & $0,66^{*}$ \\
\hline $\begin{array}{l}\mathrm{VP} \\
P V\end{array}$ & - & - & - & - & $0,89 * * *$ \\
\hline
\end{tabular}

ns, ${ }^{*},{ }^{* \star},{ }^{* \star *}$ - não significativo, $(\mathrm{P}, 0,05),(\mathrm{P}<0,01),(\mathrm{P}<0,001)$ pelo teste $\mathrm{T}$, respectivamente.

$n s,{ }^{*},{ }^{* *},{ }^{* *}-$ not significant, $(P<.05),(P<.01),(P<.001)$ by $F$ test, respectively.

variáveis medidas, fato justificável por se tratar do período de estabelecimento, quando as plantas ainda estão investindo em ocupação horizontal do espaço. Divergência genética

$\mathrm{Na}$ avaliação da diversidade genética, utilizando as variáveis canônicas, obtiveram-se os autovalores associados às variáveis canônicas, a variância acumulada (\%) e os respectivos coeficientes de ponderação com base nas sete variáveis avaliadas (Tabela 5). Observou-se que as duas primeiras variáveis canônicas explicaram $83,8 \%$ da variação total $\left(\mathrm{vc}_{1}=64,7 \%\right.$ e $\mathrm{vc}_{2}=19,1 \%$ ), sendo assim utilizadas para a identificação dos caracteres de menor importância.

Considerando que as variáveis com maior coeficiente de ponderação (elemento do autovetor) nas variáveis canônicas de autovalor inferior a 0,70, serão as de menor importância para explicar a dispersão dos genótipos, verificou-se que as variáveis de menor interesse foram: vigor das plantas, cobertura do solo e altura. Em razão da própria invariância dos dados na análise univariada (Tabela 1), a variável índice de sobrevivência não pode ser considerada discriminante. Por outro lado, foram consideradas discriminantes as variáveis produção de proteína bruta, produção de matéria seca e crescimento lateral dos estolões. A variável produção de proteína bruta apresentou o maior coeficiente de ponderação $(0,815)$ na variável canônica de maior autovalor $(64,7 \%$ da variância total), sendo o principal fator discriminante entre os genótipos no plano bidimensional. No entanto, esses resultados devem ser considerados com ressalva, devido à presença de colinearidade, decorrente de elevadas estimativas de correlações entre as características. De acordo com Carvalho (1995), a presença de alta correlação entre os caracteres avaliados produz efeitos adversos nos procedimentos canônicos, tornando os resultados inadequados para análise.

Tabela 5 - Estimativas das variâncias (autovalores, $\lambda$ ) associadas às variáveis canônicas e respectivos coeficientes de ponderação (autovetores) de sete variáveis em nove acessos e duas cultivares de amendoim forrageiro em Rio Branco-AC

Table 5 - Estimates of variances (eigenvalues, $\lambda$ ) associated to the canonic variables and respective ponderation coefficients of seven variables in nine acessions and two cultivars of forage peanut in Rio Branco-AC

\begin{tabular}{|c|c|c|c|c|c|c|c|c|}
\hline \multirow[t]{2}{*}{$\lambda$} & \multirow[t]{2}{*}{$\begin{array}{c}\text { Variância acumulada (\%) } \\
\text { Accumulated variance }\end{array}$} & \multicolumn{7}{|c|}{$\begin{array}{l}\text { Variáveis } \\
\text { Variables }\end{array}$} \\
\hline & & $\begin{array}{l}\mathrm{PMS}^{1} \\
D M Y^{1}\end{array}$ & $\begin{array}{l}\mathrm{PPB}^{2} \\
C P P^{2}\end{array}$ & $\begin{array}{l}\mathrm{CLE}^{3} \\
L S G^{3}\end{array}$ & $\begin{array}{l}\mathrm{CS}^{4} \\
G C^{4}\end{array}$ & $\begin{array}{l}\mathrm{VP}^{5} \\
P V^{5}\end{array}$ & $\begin{array}{l}\mathrm{AP}^{6} \\
P H^{6}\end{array}$ & $\begin{array}{l}\mathrm{ISM}^{7} \\
\operatorname{ISCS} S^{7}\end{array}$ \\
\hline 26,0447 & 64,7077 & $-0,1779$ & 0,815 & 0,0843 & $-0,3547$ & $-0,3539$ & $-0,2099$ & 0,043 \\
\hline 7,6848 & 83,8005 & 0,6814 & 0.3645 & 0,4598 & 0,1276 & 0,3733 & 0,1552 & $-0,1086$ \\
\hline 3,9140 & 93,5248 & 0,0998 & 0,144 & $-0,4651$ & $-0,1708$ & $-0,1187$ & 0,6723 & $-0,5077$ \\
\hline 1,9165 & 98,2864 & 0,1152 & 0,2455 & $-0,4393$ & 0,6679 & $-0,0424$ & $-0,4403$ & $-0,3031$ \\
\hline 0,3629 & 99,1880 & $-0,2237$ & 0,0502 & $-0,1681$ & $-0,4029$ & 0,7392 & $-0,3165$ & $-0,3322$ \\
\hline 0,2791 & 99,8815 & $-0,6537$ & 0,1795 & 0,4038 & 0,4458 & 0,1727 & 0,3269 & $-0,205$ \\
\hline 0,0477 & 100,000 & $-0,059$ & 0,2952 & $-0,4253$ & 0,1471 & 0,3786 & 0,2811 & 0,696 \\
\hline
\end{tabular}

${ }_{1}^{1}$ Produção de matéria seca; ${ }^{2}$ Produção de proteína bruta; ${ }^{3}$ Crescimento lateral dos estolões; ${ }^{4}$ Cobertura do solo; ${ }^{5}$ Vigor das plantas;

${ }^{6}$ Altura das plantas; ${ }^{7}$ Índice de sobrevivência das mudas.

${ }_{1}^{1}$ Dry matter yield; ${ }^{2}$ Crude protein production; ${ }^{3}$ Lateral stolon growht; ${ }^{4}$ Ground cover; ${ }^{5}$ Plant vigor; ${ }^{6}$ Plant height; ${ }^{7}$ Index of stolon cuttings survival. 
A partir dos autovetores associados às variáveis canônicas principais, foram obtidos os escores dos 11 genótipos. A dispersão gráfica dos escores das duas variáveis canônicas principais está apresentada na Figura 1. Os escores foram plotados em um espaço bidimensional, em que a distância desses pontos é proporcional ao grau de dissimilaridade entre os genótipos. Subjetivamente, os genótipos podem ser agrupados em quatro conjuntos: o primeiro com os acessos Ap 31 e Ap 11, o segundo com o acesso Ar 11, o terceiro com os acessos Ap 05, Ap 15, Ap 61, Ar 10 e a cultivar Belmonte, o quarto conjunto com os acessos Ap 39, Ap 65 e a cultivar Amarillo. A dispersão gráfica dos escores pode ser utilizada em uma primeira interpretação da divergência genética entre os genótipos, identificando os genótipos menos divergentes entre si e os mais divergentes. Desse modo, pode-se inferir que os genótipos menos divergentes entre si são aqueles pertencentes a cada conjunto, e os mais divergentes, aos conjuntos mais distantes um do outro no gráfico de dispersão.

A análise de agrupamento realizada pelo método de otimização de Tocher, com base na distância generalizada de Mahalanobis, formou quatro grupos heteróticos (Tabela 6). O primeiro grupo foi formado pelos genótipos Ar 10, Belmonte, Ap 65 e Amarillo, o segundo grupo pelos acessos Ap 05, Ap 61, Ap 15, Ap 11 e Ar 11. Os terceiro e quarto grupos foram constituídos por apenas um acesso, sendo o acesso Ap 31 pertencente ao terceiro grupo e o acesso Ap 39 ao quarto grupo. O acesso Ap 39 apresentou valores médios a altos para todas as características avaliadas e o acesso Ap 31, valores baixos para todos os caracteres avaliados, exceto para altura, em que esta foi intermediária. Observa-se também, na Tabela 6 , que as cultivares Amarillo e Belmonte pertencem ao mesmo grupo, portanto, a distância entre elas é pequena, indicando que essas duas cultivares são aparentadas, ou pelo menos, oriundas de genitores com alto grau de parentesco.

Comparando os grupos formados pelo gráfico de dispersão dos escores das duas variáveis canônicas principais com os agrupamentos formados pelo método de Tocher, observa-se que houve algumas discordâncias dos resultados. O acesso Ar 11, que pelo gráfico de dispersão dos escores das duas variáveis canônicas principais, formou um grupo separado, pelo método de Tocher, está em um grupo junto com outros acessos, incluindo o acesso Ap 11. Este último acesso, pelo gráfico de dispersão das variáveis canônicas, está em grupo juntamente com o Ap 31, que, pelo método de Tocher, ficou sozinho em um grupo. A causa dessas discordâncias pode ser, como já mencionado, as altas correlações entre os caracteres avaliados, o que inviabiliza as análises de variáveis canônicas. Portanto, nesse trabalho, os agrupamentos formados pelo método de Tocher são os mais confiáveis.

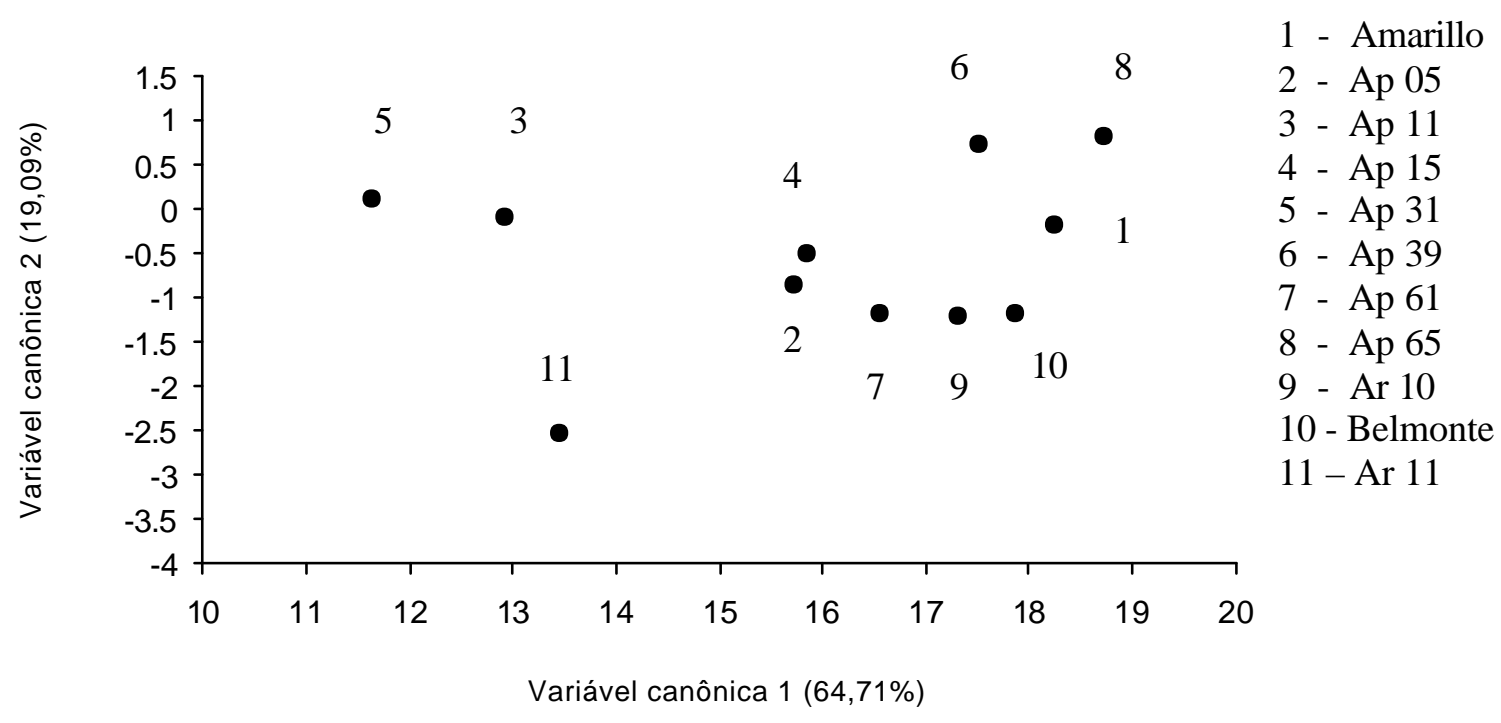

Figura 1 - Diagrama de dispersão de nove acessos e duas cultivares de amendoim forrageiro (Arachisspp.) obtido pela análise de variáveis canônicas. Rio Branco-AC.

Figure 1 - Dispersion diagram of nine accessions and two cultivars of forage peanut (Arachis spp.) obtained by the canonical traits analysis. Rio Branco-AC.

R. Bras. Zootec., v.32, n.6, p.1569-1577, 2003 (Supl. 1) 
Tabela 6 - Análise de agrupamento pelo método de otimização de Tocher, obtido por meio das distâncias generalizada de Mahalanobis $\left(D^{2}\right)$, de nove acessos e duas cultivares de amendoim forrageiro, em Rio Branco, AC

Table 6 - Cluster analysis by Tocher otimization method from Mahalanobis generalized distance $\left(D^{2}\right)$ of nine accessions and two cultivars of forage peanut in Rio Branco-AC

\begin{tabular}{|c|c|}
\hline $\begin{array}{l}\text { Grupo } \\
\text { Group } \\
\end{array}$ & $\begin{array}{l}\text { Genótipos } \\
\text { Genotypes }\end{array}$ \\
\hline 1 & 9 (Ar 10), 10 (Belmonte), 8 (Ap 65) e 1 (Amarillo) \\
\hline 2 & 2 (Ap 05), 7 (Ap 61), 4 (Ap 15), 3 (Ap 11) e 11 (Ar 11) \\
\hline 3 & $5(\mathrm{Ap} \mathrm{31)}$ \\
\hline 4 & $6($ Ap 39) \\
\hline
\end{tabular}

\section{Conclusões}

As cultivares Belmonte e Amarillo e os acessos Ap 65, Ap 39, Ar 10 e Ap 61 destacaram-se pela excelente adaptação e velocidade de crescimento e elevado teor de proteína bruta, durante o período de estabelecimento nas condições ambientais de Rio Branco, Acre.

Entre os quatro grupos heteróticos, o grupo formado pelo acesso Ap 39 destacou-se dos demais, por apresentar valores médios a altos para todas as características avaliadas, de acordo com a análise de agrupamento realizada pelo método de otimização de Tocher, com base na distância generalizada de Mahalanobis.

Para que os materiais promissores possam ser recomendados para uso nos sistemas intensivos de produção de bovinos no Acre, devem ser desenvolvidos estudos adicionais com relação à: 1) produtividade e qualidade de materia seca no período chuvoso e seco; 2) ocorrência de pragas e doenças; 3 ) produção de sementes; 4) adaptação a solos de baixa permeabilidade; 5) compatibilidade com gramíneas forrageiras e espécies arbóreas e arbustivas perenes; 6) produção animal e persistência sob pastejo.

\section{Literatura Citada}

ARGEL, P.J. Regional experience with forageArachis in Central America and Mexico. In: KERRIDGE, P.C.; HARDY, B. (Eds.). Biology and agronomy of forage Arachis. Cali, Colombia: CIAT, 1994. p.134-143.

ARGEL, P.J.; PIZARRO, E.A. Germplasm case study:Arachis pintoi. In: Pasture for the tropical lowlands: CIAT's Contribution. Cali, Colombia: CIAT, 1992. p.57-73.
ARGEL, P.J.; VILLARREAL, M.Nuevo maní forrajero perene (Arachis pintoi Krapovickas Y Gregory) Cultivar Porvenir (CIAT 18744): leguminosa herbácea para alimentación animal, el mejoramiento y conservación del suelo e el embellecimiento del paisaje. Local: Ministério de Agricultura y Ganaderia de Costa Rica (MAG)/ Centro Internacional de Agricultura Tropical (CIAT), 1998. 32p. (Boletín Técnico)

BARCELLOS, A.O.; ANDRADE, R.P.; KARIA, C.T. et al. Potencial e uso de leguminosas dos gêneros Stylosanthes, Arachis e Leucaena. In: SIMPÓSIO SOBRE MANEJO DA PASTAGEM, 17., 2000, Jaboticabal. Anais... Jaboticabal: Fundação de Estudos Agrários "Luiz de Queiroz", 2000. p.297-358.

BARUCH, Z.; FISHER, M.J. Effecto del metodo de siembra y de la textura del suelo sobre el crescimiento y desarrollo de Arachis pintoi. In: REUNIÓN DE SABANAS, 1., 1992, Brasília. Anais... Cali: CIAT, 1992. p.527-538. (CIAT. Documento de Trabajo, 117).

CARNEIRO, J.C.; VALENTIM, J.F.; PESSÔA, G.N. Avaliação agronômica do potencial forrageiro de Arachis spp. nas condições ambientais do Acre. In: REUNIÃO ANUAL DA SOCIEDADE BRASILEIRA DE ZOOTECNIA, 37 ., 2000, Viçosa, MG. Anais... Viçosa, MG: Sociedade Brasileira de Zootecnica/Gnosis, [2000]. CD ROM. Forragicultura. FOR-0392.

CARVALHO, S.P. Métodos alternativos de estimação de coeficiente de trilha e índice de seleção sob multicolinearidade. Viçosa, MG: Universidade Federal de Viçosa, 1995. 163p. Tese (Doutorado em Genética e Melhoramento de Plantas) - Universidade Federal de Viçosa, 1995.

COOK, B.G.; JONES, R.M.; WILLIAMS, R.J. Regional experience with forage Arachis in Australia. In: KERRIDGE, P.C.; HARDY, B. (Eds.). Biology and agronomy of forage Arachis. Cali, Colombia: CIAT, 1994. p.158-168.

CRUZ, C.D. Programa GENES: aplicativo computacional em genética e estatística. Viçosa, MG: Universidade Federal de Viçosa, 1997. 390p.

DAHER, R.F.; VÁZQUES, H.M.; PEREIRA, A.V. et al. Introdução e avaliação de clones de capim-elefante (Pennisetum purpureum Schum.) em Campos dos Goytacazes, RJ. Revista Brasileira de Zootecnia, v.29, n.5, p.1296-1301, 2000.

DAMÉ, P.R.V.; SIEWERDT, L.; REIS, J.C.L. Amendoim forrageiro: qualidade da forragem de acessos no litoral do Rio Grande do Sul. In: REUNIÃO ANUAL DA SOCIEDADE BRASILEIRA DE ZOOTECNIA, 35., 1998, Botucatu, SP. Anais... Botucatu: Sociedade Brasileira de Zootecnia/Gnosis, [1998]. CD ROM. Forragicultura. FOR-0230.

de la CRUZ, R.; SUÁREZ, S.; FERGUSON, J.E. The contribution of Arachis pinto $i$ as a ground cover in some farming systems of tropical America. In: KERRIDGE, P.C., HARDY, B. (Eds.). Biology and agronomy of forage Arachis. Cali, Colombia: CIAT, 1994. p.102-108.

FISHER, M.J.; CRUZ, P. Some ecophysiological aspects of Arachis pintoi. In: KERRIDGE, P.C.; HARDY, B. (Eds.). Biology and agronomy of forage Arachis. Cali, Colombia: CIAT, 1994. p.53-70.

FERREIRA, D.F. Análises estatísticas por meio do Sisvar para Windows versão 4.0. In: REUNIÃO ANUAL DA REGIÃO BRASILEIRA DA SOCIEDADE INTERNACIONAL DE BIOMETRIA, 45., 2000, São Carlos. Resumos expandidos... São Carlos: Universidade Federal de São Carlos, 2000. p.255-258. 
FRANCO, M.A.; MESA, E.; FRANCO, L.H. Análisis de la información disponibler en al base da datos sobre localidades y evaluaciones de germoplasma en Centro América, Mexico Y El Caribe. Programa de Pastos Tropicales, Centro Internacional de Agricultura Tropical (CIAT), Cali, Colômbia. 1992. 208p.

EMBRAPA. Boletim Agrometeorológico 1995. Rio Branco: Embrapa-CPAF/Acre, 1995. n.p. (Embrapa-CPAF/Acre, Boletim Agrometeorológico 6).

FRENCH, E.C.; PRINE, G.M.; OCUMPAUGH, W.R. et al. Regional experience with forageArachis in the United States. In: KERRIDGE, P.C.; HARDY, B. (Eds.). Biology and agronomy of forage Arachis. Cali, Colombia: CIAT, 1994. p.169-186.

IBGE. Instituto Brasileiro de Geografia e Estatística. 1997. Anuario Estatistico do Brasil. Rio de Janeiro: IBGE, v.57, 1997.

Instituto Nacional de Pesquisas Espaciais (INPE). 2000. http://www.inpe.br/Informacoes_Eventos/amz/amz.html. Folder PRODES.

LASCANO, C.E. Nutritive value and animal production of forage Arachis. In: KERRIDGE, P.C.; HARDY, B. (Eds.).Biology and agronomy of forage Arachis. Cali, Colombia: CIAT, 1994. p.109-121.

NASCIMENTO FILHO, F.J.; ATROCH, A.L.; SOUSA, N.R. et al. Divergência genética entre clones de guaranazeiro. Pesquisa Agropecuária Brasileira, v.36, n.3, p.501-506, 2001.

PEREZ, N.B.; MARACHIN, G.E.; NABINGER, C. Influência de diferentes métodos de estabelecimento de Arachis pintoi sobre a produção e a composição botânica da pastagem nativa e de coastcross-1. In: REUNIÃO ANUAL DA SOCIEDADE BRASILEIRA DE ZOOTECNIA, 36., 1999, Porto Alegre. Anais...Porto Alegre, RS: Sociedade Brasileira de Zootecnia/ Gnosis, [1999]. CD ROM. Avaliação de forrageiras. Forragicultura. FOR-097.

PEREZ, N.B.; NABINGER, C.; MARACHIN, G.E. Desenvolvimento inicial deArachis pintoiintroduzido sobre pastagem nativa. In: REUNIÃO ANUAL DA SOCIEDADE BRASILEIRA DE ZOOTECNIA, 36., 1999, Porto Alegre.Anais... Porto Alegre, RS: Sociedade Brasileira de Zootecnia/Gnosis, [1999]. CD ROM. Avaliação de forrageiras. Forragicultura. FOR-091.

PIMENTEL GOMES, F. Curso de estatística experimental. 13.ed. Piracicaba: Escola Superior de Agricultura "Luiz de Queiroz", 1990. 467p.

PIZARRO, E.A.; CARVALHO, M.A.; VALLS, J.F. et al.Arachis spp.: evaluación agronomica en areas bajas del cerrado. In: REUNIÓN DE SABANAS,1, 1992, Anais... Cali: CIAT, 1992. p.353-356. (CIAT. Documento de Trabajo, 117).

PIZARRO, E.A.; CARVALHO, M.A. Cerrado: introdución y evaluación agronomica de forrajeras tropicales. In: REUNIÓN DE SABANAS, 1., 1992, Cali. Anais... Cali: CIAT, 1992. p.1-68. (Documento de Trabajo, 117)
PIZARRO, E.A.; RINCÓN, A. Regional experiences with forage Arachis in South America. In: KERRIDGE, P.C.; HARDY, B. (Eds.). Biology and agronomy of forage Arachis. Cali, Colombia: CIAT, 1994. p.144-157.

PRINE, G.M.; DUNAVIN, L.S.; MOORE, J.E. et al. 'Florigraze' rhizoma peanut, a perennial forage legume. Florida: University of Florida-Agriculture Experimental Station, 1981. 22p. (Circ. S-275)

PRINE, G.M.; DUNAVIN, L.S.; GLENNON, R.J. et al. Arbrook rhizoma peanut, a perennial forage legume. Florida: University of Florida-Agriculture Experimental Station, 1986. 16p. (Circ. S-332)

RIBEIRO, F.E.; SOARES, A.R.; RAMALHO, M.A.P. Divergência genética entre populações de coqueiro-gigante-dobrasil. Pesquisa Agropecuária Brasileira, v.32, n.9, p.1615-1622, 1999.

SANTANA, J.R.; PEREIRA, J.M.; RESENDE, C.P.Avaliação da consorciação deBrachiaria dictyoneura Stapf comArachis pintoi Krapov. \& Gregory sob pastejo. In: REUNIÃO ANUAL DA SOCIEDADE BRASILEIRA DE ZOOTECNIA, 35., 1998, Botucatu. Anais... Botucatu: Sociedade Brasileira de Zootecnia/Gnosis, [1998]. CD ROM. Forragicultura. FOR-0273.

SILVA, D.J. Análise de alimentos: métodos químicos e biológicos. Viçosa, MG: Universidade Federal de Viçosa, 1990. 165p.

SCOTT, A.J.; KNOTT, M. A cluster analysis method for grouping means in the analysis of variance.Biometrics, v.30, n.3, p.507-512, 1974.

VALENTIM, J.F.; CARNEIRO, J.C. Pueraria phaseoloides e Calopogonium mucunoides. In: SIMPÓSIO SOBRE MANEJO DA PASTAGEM, 17., 2000. SIMPÓSIO SOBRE MANEJO DA PASTAGEM: A PLANTA FORRAGEIRA NO SISTEMA DE PRODUÇÃO, 17. Anais... Piracicaba: Fundação de Estudos Agrários "Luiz de Queiroz", 2001. p.427-458.

VALENTIM, J.F.; CARNEIRO, J.C.; VAZ, F.A. et al. Produção de mudas deArachis pintoi cv. Belmonte no Acre.Rio Branco: Embrapa Acre, 2000. 4p. (Embrapa Acre. Instruções Técnicas, 33).

VALENTIM, J.F.; CARNEIRO, J.C.; VAZ, F.A. et al. Velocidade de estabelecimento de acessos de amendoim forrageiro nas condições ambientais do Acre. In: REUNIÃO ANUAL DA SOCIEDADE BRASILEIRA DE ZOOTECNIA, 38., 2001, Piracicaba. Anais... Piracicaba: Sociedade Brasileira de Zootecnia/MADEWITH Macromedia, [1998]. CD ROM. Forragicultura. FOR-0942.

Recebido em: 09/10/01 Aceito em: 19/03/02 